\title{
Reliability Assessment and Residual Life Estimation of Concrete Girder Bridges Strengthened by Carbon Fiber during the Service Stage
}

\author{
Haoyun Yuan $\mathbb{D}^{1},{ }^{1}$ Wei Hou, ${ }^{1}$ Leping Ren, ${ }^{1}$ and Xiaojin $\mathrm{Zhao}^{2}$ \\ ${ }^{1}$ Department of Bridge Engineering, Chang'an University, Xi'an 710064, China \\ ${ }^{2}$ Shanxi Key Laboratory of Bridge Engineering Disaster Prevention and Mitigation, \\ Shanxi Transportation Technology Research \& Development Co., Ltd., Taiyuan 030006, China
}

Correspondence should be addressed to Haoyun Yuan; 2016021007@chd.edu.cn

Received 8 February 2020; Revised 24 June 2020; Accepted 22 September 2020; Published 9 October 2020

Academic Editor: Chao Wu

Copyright ( $(2020$ Haoyun Yuan et al. This is an open access article distributed under the Creative Commons Attribution License, which permits unrestricted use, distribution, and reproduction in any medium, provided the original work is properly cited.

In recent decades, carbon fiber reinforced plastics (CFRP) have been widely used to repair and maintain concrete structures around the world. Since the parameter uncertainties of load and resistance are very important for the reliability assessment of RC bridge strengthened by CFRP, this paper presents a method to estimate the reliability and residual life of RC bridges strengthened by CFRP. In the proposed method, uncertainties of material properties, geometry parameters, load model, and time-dependent resistance model are taken into account. The proposed method combines the inverse reliability method and the calculation method of load and resistance of RC bridge strengthened by CFRP and is illustrated by an example RC bridge strengthened by CFRP during the service stage. The results indicate that the proposed approach can provide valid information regarding parameter uncertainties for the reliability of RC bridge strengthened by CFRP during the service stage. Additionally, the effects of parameter uncertainty of the reliability and residual life of RC bridge strengthened by CFRP during the service stage are analyzed and discussed. The proposed method is more robust and reliable than the traditional method.

\section{Introduction}

High-performance materials, such as carbon fiber reinforced plastics (CFRP) and ultrahigh-performance concrete [1], have extremely high strength-to-weight ratios and are suitable for efficient repair of deficient structural members. These materials mentioned above can be utilized for rapid replacement and require less cost compared to traditional methods. The use of the CFRP to repair and strengthen reinforced concrete (RC) structures has been well applied.

With the increase of traffic volume and the deterioration of atmospheric environment, bridges often fail to achieve the expected service life. Accordingly, maintenance and reinforcement should be conducted regularly to meet the requirements of loading capacity and long service. In recent years, CFRP have been commonly used to strengthen concrete bridges. Gajdosova and Juraj [2] presented an investigation into the performance of slender rectangular reinforced concrete columns strengthened with CFRP in two manners. Dai et al. [3] presented the results of an experimental study on the behavior of concrete confined by CFRP jackets with a large rupture strain. Karimi et al. [4] conducted a composite column consisting of steel, concrete, and CFRP and assessed it through experimental testing and analytical modeling. Sun et al. [5] studied the seismic behavior of hollow bridge columns retrofitted with CFRP. Delgado et al. [6] presented the experimental analysis of retrofit solutions using CFRP sheets along the piers' entire height to prevent shear failure. Gu et al. [7] presented the results of a research program that evaluated the confinement effectiveness of the type and the amount of CFRP used to retrofit circular concrete columns. Kumar et al. [8] and Baah [9] investigated the performance of CFRP to strengthen the concrete columns. Grace et al. $[10,11]$ applied the CFRP to 
reinforced T-beam and Composite Posttensioning System. Yang et al. $[12,13]$ studied the behaviors of CFRP in application of bridges. It can be seen that CFRP have been widely used in structural engineering but were only limited to deterministic analysis.

However, there are currently few studies concerning the change of reliability before and after reinforcement, as well as whether the service life requirements could be satisfied after reinforcement. Therefore, it is necessary to evaluate the reliability before and after reinforcement of RC bridges during the service stage. In recent years, some scholars have studied the reliability of CFRP reinforced bridges in service. Sun et al. [14] investigated a number of CFRP reinforcement tests and obtained uncertain parameters of calculation model of reinforced concrete components, and they proposed that aging and degradation of bonding surface of CFRP cannot be considered after reinforcement. Du et al. [15] established the limit state equation of a bridge strengthened with CFRP through many tests, calculated the reliability index, and verified the feasibility of the bridge reinforcement design. Forouzannia et al. [16] investigated the calibration of flexural resistance factors for load and resistance factor design of concrete bridge girders prestressed with CFRP. However, limited studies have been carried out to investigate the influence of parameter uncertainty on reliability index, and the time-dependent parameters have not been fully considered in the reliability models mentioned above.

The current bridge design code is developing in the direction of performance-based orientation, and the determination of design parameter is to meet the requirement of the prescribed reliability of bridge structures, especially the residual life of bridges during the service stage. The structure of this paper is as follows. Firstly, time-dependent resistance model of bridges strengthened with CFRP is developed. Secondly, the load model of bridges strengthened with CFRP is proposed. After that, the calculation method to assess the reliability of bridges strengthened with CFRP is introduced. Finally, with an example bridge, the time-dependent reliability index before and after reinforcement, and the residual life of RC girder bridge reinforced by CFRP are obtained, and the service life of the bridge after reinforcement is predicted using the inverse reliability method. Additionally, the variation coefficients of dead load, live load, and cross-sectional area of corroded steel bars are analyzed and discussed.

\section{Time-Dependent Resistance Model of Bridges Strengthened with CFRP}

Time-dependent resistance model of bridges strengthened with CFRP was developed based on initial rust time model of steel bars, corrosion rate model of steel bars, corrosion depth model of steel bars when the protective layer cracks, cracking time of the protective layer of concrete, time-dependent section area model of corroded steel bars, time-dependent model of yield strength and corrosion rate of corroded steel bars, time-dependent model of concrete strength, and cooperative working coefficient model of concrete and steel bar, which have been studied, but according to author's knowledge, the reliability index and residual life estimation using the proposed inverse reliability method have not been investigated in the previous references. In calculating reliability index and residual life estimation using inverse reliability, the models of mean and standard deviation of timedependent resistance after reinforcement are very important. The details of the time-dependent resistance model of bridges strengthened with CFRP are carefully described below.

2.1. Initial Rust Time Model of Steel Bars. The initial rust time of steel bars of bridges after service has been studied by many scholars. Niu and Cheng [17] established the carbonation model of concrete structures. When the atmosphere carbonates to the surface of steel bar (the carbonation depth is equal to the protective thickness of concrete layer $C)$, the $t$ is the time when steel bar begins to rust. Peng et al. [18] improved the prediction model of carbonization depth through taking multiple factors such as water cement ratio and calcium oxide content into account. However, the initial rust time of steel bars of real bridges calculated from the above model is mostly over 80 years, which was not consistent with the engineering practice.

Reference [19] introduced the time model of initial rust of steel bars as follows:

$$
t_{0}=\frac{C^{2}}{4 D_{c}}\left[\operatorname{erf}^{-1}\left(\frac{C_{0}-C_{c r}}{C_{0}}\right)\right]^{-2},
$$

where $t_{0}$ is the initial rust time of steel model (year); $C$ is the protective thickness of concrete layer $(\mathrm{cm})$; and $D_{c}$ is diffusion coefficient influenced by many factors such as concrete compactness and mix ratio. A range of mean values between 0.32 and 2.58 is given by [20] $\left(\mathrm{cm}^{2} /\right.$ year); erf is the error function, $\operatorname{erf}(z)=2 / \sqrt{\pi} \int_{0}^{z} e^{-u^{2}} \mathrm{~d} u ; C_{0}$ is the chloride ion concentration on concrete surface (\%); and $C_{\mathrm{cr}}$ is the critical chloride ion concentration, and a range of mean values (\%) between $0.027 \%$ and $0.045 \%$ is given by [21]

2.2. Corrosion Rate Model of Steel Bars. Because the corrosion rate of steel bar is different before and after expansion cracking, the model of corrosion rate of steel bar is given in [22].

(1) Before cracking of protective layer $\left(t \leq t_{\mathrm{cr}}\right)$ :

$$
v_{0}=46 k_{1} \cdot k_{2} \cdot e^{0.04 T} \cdot\left(R_{H}-0.45\right)^{2 / 3} \cdot C^{-1.36} \cdot f_{\mathrm{cu}}^{-1.83} \text {. }
$$

(2) After cracking of protective layer $\left(t>t_{\mathrm{cr}}\right)$ :

$$
v_{1}= \begin{cases}2.5 v_{0}, & v_{0}>0.08 \\ 4 v_{0}-187.5 v_{0}^{2}, & v_{0} \leq 0.08\end{cases}
$$

where $t_{\mathrm{cr}}$ is the cracking time of protective layer (year); $v_{0}$ is the corrosion rate of steel bars before cracking of protective layer (cm/year); $\nu_{1}$ is the corrosion rate of steel bars after cracking of protective layer ( $\mathrm{cm} /$ year); $k_{1}$ is the correction 
factor of position of steel bars; 1.0 is for the steel bars in the middle and 1.6 is for those in the corner; $k_{2}$ is the environmental correction factor; $3.0-4.0$ is for the outdoor humid environment; $2.5-3.5$ is for the outdoor dry environment; $T$ is the environmental temperature $\left({ }^{\circ} \mathrm{C}\right) ; R_{\mathrm{H}}$ is the ambient humidity (\%); $C$ is the concrete cover thickness $(\mathrm{mm})$; and $f_{c u}$ is cubic compressive strength (MPa).

\subsection{Corrosion Depth Model of Steel Bars When Protective} Layer Cracks. The corrosion depth of steel bars when the protective layer cracks [23] is as follows:

$$
\delta_{\mathrm{cr}}=k_{\mathrm{mcr}} \cdot k_{\mathrm{crs}} \cdot\left(0.008 \frac{C}{d}+0.00055 f_{\mathrm{cu}}-0.002\right) \text {, }
$$

where $\delta_{\text {cr }}$ is the corrosion depth of steel bars when the protective layer cracks $(\mathrm{mm}) ; k_{\mathrm{mcr}}$ is the uncertainty coefficient of calculation model; $k_{\mathrm{crs}}$ is the position influence coefficient of steel bars, 1.0 at corner and 1.35 at noncorner; $C$ is the thickness of protective layer $(\mathrm{mm})$; and $D$ is the diameter of steel bar ( $\mathrm{mm})$.

2.4. The Cracking Time of Protective Layer of Concrete. The cracking time of protective layer of concrete is the initial rust time of steel bar plus the time from initial rust to cracking of protective layer. From (1), (2), and (4), we can indicate that the cracking time $t_{\tau}$ (year) of protective layer is

$$
t_{\tau}=t_{0}+\frac{\delta_{\mathrm{cr}}}{v_{0}} .
$$

2.5. Time-Dependent Section Area Model of Corroded Steel Bars. It can be derived from the above analysis as follows:

$$
A_{s}(t)= \begin{cases}A_{s 0}, & t<t_{0}, \\ A_{s 0}\left[1-\frac{v_{0}\left(t-t_{1}\right)}{d}\right]^{2}, & t_{0} \leq t<t_{\tau}, \\ A_{s 0}\left[1-\frac{v_{0}\left(t_{\tau}-t_{0}\right)+v_{1}\left(t-t_{\tau}\right)}{d}\right]^{2}, & t \geq t_{\tau},\end{cases}
$$

where $A_{s 0}$ is the initial section area of steel bar $\left(\mathrm{mm}^{2}\right)$ and $A_{s}(t)$ is the time-dependent section area $\left(\mathrm{mm}^{2}\right)$.

2.6. Time-Dependent Model of Yield Strength and Corrosion Rate of Corroded Steel Bars. A yield strength model of steel bar was established based on abundant experimental studies as follows:

$$
f_{\mathrm{ys}}=\frac{0.985-1.028 \rho_{s}}{1-\rho_{s}} f_{y 0}
$$

where $f_{\text {ys }}$ is the time-dependent yield strength of steel bars $(\mathrm{MPa}), \rho_{\mathrm{s}}$ is the corrosion rate of steel bars (\%), and $f_{y 0}$ is the initial yield strength of steel bars before corrosion ( $\mathrm{MPa})$.
The model of steel corrosion rate can be derived from (6):

$$
\rho_{s}= \begin{cases}0, & t<t_{0}, \\ 1-\left[1-\frac{v_{0}\left(t-t_{1}\right)}{d}\right]^{2}, & t_{0} \leq t<t_{\tau}, \\ 1-\left[1-\frac{v_{0}\left(t_{\tau}-t_{0}\right)+v_{1}\left(t-t_{\tau}\right)}{d}\right]^{2}, & t \geq t_{\tau} .\end{cases}
$$

2.7. Time-Dependent Model of Concrete Strength. According to [24], the time-dependent model of concrete in atmospheric environment is as follows:

$$
\begin{aligned}
& \mu f_{\mathrm{cu}}(t)=\mu f_{\mathrm{cu} 0} \cdot 1.4529 \cdot e^{-0.0246(\text { Int-1.7154) }}{ }^{2}, \\
& \sigma f_{\mathrm{cu}}(t)=\sigma f_{\mathrm{cu} 0} \cdot(0.0305 t+1.2368),
\end{aligned}
$$

where $\mu f_{\text {cu0 }}$ is the mean value of concrete strength measured in 28 days $(\mathrm{MPa}) ; \sigma f_{\mathrm{cu} 0}$ is the standard deviation of concrete strength measured in 28 days ( $\mathrm{MPa})$; and $t$ is the time (year).

2.8. Cooperative Working Coefficient $k_{s}$ Model of Concrete and Steel Bar. Reference [25] introduced the expression of the cooperative working coefficient of concrete and steel bar based on abundant research results and a series of tests. The expression is as follows:

$$
k_{s}=\begin{array}{ll}
1, & \rho_{s}<1.2 \%, \\
1.0168-0.014 \rho_{s}, & 1.2 \% \leq \rho_{s}<6 \%, \\
0.72+0.295 e^{-0.0651 \rho_{s},}, & 6 \% \leq \rho_{s}<20 \%, \\
0.8, & \rho_{s} \geq 20 \%,
\end{array}
$$

where $\rho_{s}$ is the steel corrosion rate (\%).

2.9. Models of Mean and Standard Deviation of Time-Dependent Resistance after Reinforcement. When the component is the first type of T-section, the structure diagram is shown in Figure 1.

When $\xi_{b} h_{0}>x>\xi_{\mathrm{cfb}} h$,

$$
f_{\mathrm{cm}} b_{f} x=k_{s} f_{y} A_{s}+E_{\mathrm{cf}} \varepsilon_{\mathrm{cf}} A_{\mathrm{cf}},
$$

where $E_{\mathrm{cf}}$ is the elastic modulus of CFRP $(\mathrm{MPa}) ; \varepsilon_{\mathrm{cf}}$ is the strain of CFRP; $A_{\mathrm{cf}}$ is the cross-sectional area of CFRP $\left(\mathrm{cm}^{2}\right)$; $\xi_{\mathrm{cfb}}$ is the critical height of CFRP when it reaches the allowable tensile strain $\left[\varepsilon_{\mathrm{cf}}\right]$ and concurrent compression of concrete, $\xi_{\mathrm{cfb}}=\left(0.8 \varepsilon_{\mathrm{cu}} / \varepsilon_{\mathrm{cu}}+\left[\varepsilon_{\mathrm{cf}}\right]+\varepsilon_{i}\right) ; \varepsilon_{\mathrm{cu}}$ is the ultimate tensile strain of concrete, taken as 0.0033 ; $\varepsilon_{i}$ is the lag strain of CFRP when considering secondary loading, taken as 0 when the secondary loading is not considered; $\left[\varepsilon_{\mathrm{cf}}\right]$ is the allowable tensile strain of CFRP $\left[\varepsilon_{\mathrm{cf}}\right]=\left(1.16-n_{\mathrm{cf}} E_{\mathrm{cf}} t_{\mathrm{cf}} /\right.$ $308000) \varepsilon_{\mathrm{cfu}}$, whose value should be less than or equal to the ultimate tensile strain of CFRP; $\varepsilon_{c f u}$ is the ultimate tensile 


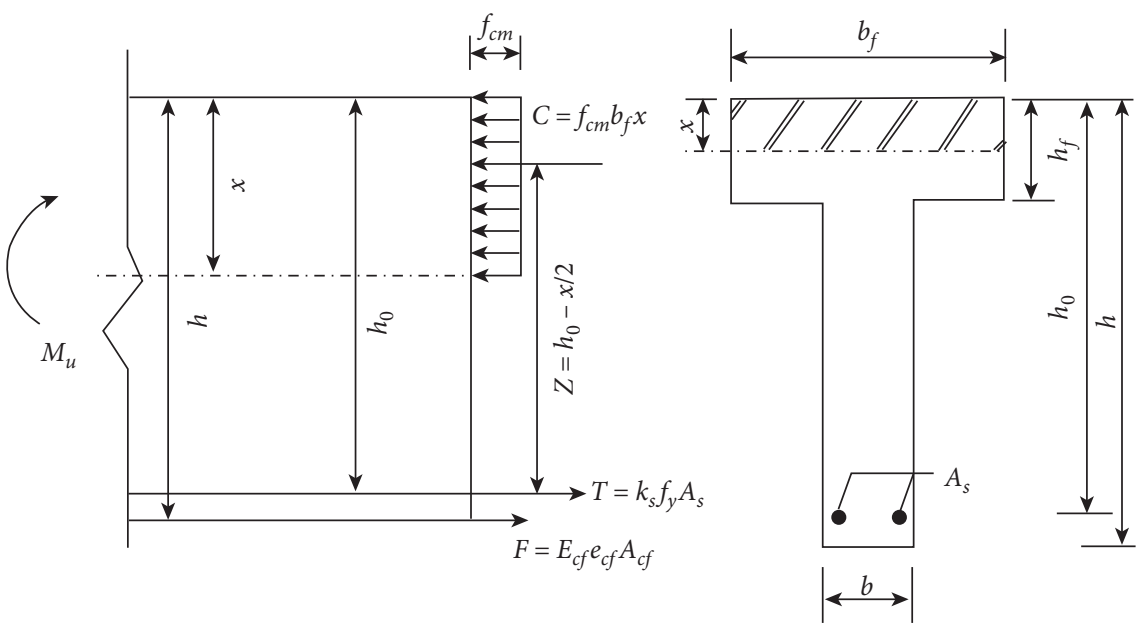

Figure 1: Structure diagram.

strain of CFRP, $\varepsilon_{\mathrm{cfu}}=\left(f_{\mathrm{cfk}} / E_{\mathrm{cf}}\right) ; f_{\mathrm{cfk}}$ is the ultimate tensile strength of CFRP (MPa); $n_{\mathrm{cf}}$ is the number of layers of CFRP; $t_{c f}$ is the thickness of CFRP (mm); $\xi_{b}$ is the relative limit height of compression zone of flexural components.

In addition,

$$
x=\frac{0.8 \varepsilon_{\mathrm{cu}}}{\varepsilon_{\mathrm{cu}}+\varepsilon_{\mathrm{cf}}+\varepsilon_{i}} h .
$$

From (10) and (11), the height of concrete compression zone $x$ and the tensile strain of CFRP sheet $\varepsilon_{\mathrm{cf}}$ can be obtained. Considering the uncertainties of material properties, geometric parameters, and calculation model, the mean value of resistance is expressed as follows:

$$
\mu_{R_{M_{u}}}=\mu_{k_{p}}\left[\mu_{f_{\mathrm{cm}}(t)} \mu_{b_{f}} x\left(\mu_{h_{0}}-\frac{x}{2}\right)+E_{\mathrm{cf}} \varepsilon_{\mathrm{cf}} \mu_{A_{\mathrm{cf}}}\left(\mu_{h}-\mu_{h_{0}}\right)\right] \text {. }
$$

When $x \leq \xi_{\mathrm{cfb}} h$ and the CFRP sheet is larger than or equal to its allowable tensile strain, the moment of concrete in the compression zone is calculated as follows:

$$
\begin{aligned}
\mu_{R_{M_{u}}}= & \mu_{\mathrm{k}_{\mathrm{p}}}\left[\mu_{f_{y}(t)} \mu_{k_{s}} \mu_{A_{s}(t)}\left(\mu_{h_{0}}-0.5 \xi_{\mathrm{cfb}} \mu_{b}\right)\right. \\
& \left.+E_{\mathrm{cf}}\left[\varepsilon_{\mathrm{cf}}\right] \mu_{A_{\mathrm{cf}}} \mu_{h}\left(1-0.5 \xi_{\mathrm{cfb}}\right)\right],
\end{aligned}
$$

where $\mu_{k}$ is the indefinite coefficient of calculation model; $\mu_{f_{y}(t)}$ is the time-dependent strength of steel bar (MPa); $\mu_{A_{s}(t)}$ is the time-dependent cross-sectional area of steel bar $\left(\mathrm{mm}^{2}\right) ; \mu_{f_{\mathrm{cm}}(t)}$ is the bending compressive strength of timedependent concrete ( $\mathrm{MPa})$.

According to (12) and (13), the expression of standard deviation can be obtained as follows:

$$
\begin{aligned}
\sigma_{R_{M_{u}(t)}^{2}}^{2}= & {\left.\left[\frac{\partial R_{M_{u}(t)}}{\partial f_{y}(t)}\right]^{2}\right|_{u} \sigma_{f_{y}(t)}^{2}+\left.\left[\frac{\partial R_{M_{u}(t)}}{\partial f_{\mathrm{cm}}(t)}\right]^{2}\right|_{u} \sigma_{f_{\mathrm{cm}}(t)}^{2}+\left.\left[\frac{\partial R_{M_{u}(t)}}{\partial A_{s}(t)}\right]^{2}\right|_{u} \sigma_{A_{s}(t)}^{2} } \\
& +\left.\left[\frac{\partial R_{M_{u}(t)}}{\partial h_{0}}\right]^{2}\right|_{u} \sigma_{h_{0}}^{2}+\left.\left[\frac{\partial R_{M_{u}(t)}}{\partial b_{f}}\right]^{2}\right|_{u} \sigma_{b_{f}}^{2}+\left.\left[\frac{\partial R_{M_{u}(t)}}{\partial k_{p}}\right]^{2}\right|_{u} \sigma_{k_{p}}^{2}+\left.\left[\frac{\partial R_{M_{u}(t)}}{\partial h}\right]^{2}\right|_{u} \sigma_{h}^{2} \\
& +\left[\frac{\partial R_{M_{u}(t)}}{\partial k_{s}}\right]^{2}\left|\sigma_{u}^{2}+\left[\frac{\partial R_{M_{u}(t)}}{\partial A_{\mathrm{cf}}}\right]^{2}\right|_{u} \sigma_{A_{\mathrm{cf}}}^{2},
\end{aligned}
$$

where $\left.\left[\partial R_{M_{u}(t)} / \partial X_{i}\right]^{2}\right|_{u} \sigma_{X_{i}}^{2}$ is the partial derivative of $R_{M_{u}(t)}$ to $X_{i}$, and it is taken as mean value at each random variable; $\sigma_{X_{i}}$ is the standard deviation of random variable $X_{i}$.

\section{Load Model}

3.1. Dead Load Effect. From [26], the dead load does not change with time, following the normal distribution. The mean value, standard deviation, and variation coefficient of the dead load effect are as follows:

$$
\begin{aligned}
\mu_{\mathrm{SG}} & =1.0148 C G_{k}, \\
\sigma_{\mathrm{SG}} & =0.0437 C G_{k}, \\
\delta_{\mathrm{SG}} & =0.0431,
\end{aligned}
$$

where $C$ is the coefficient of dead load effect and $G_{k}$ is uniformly distributed loads. For simply supported girder bridges, $C=\left(l^{2} / 8\right)$.

3.2. Living Load Effect Model of Vehicle. Generally, a dimensionless parameter $K_{\mathrm{SQ}}$ is used to express the ratio of the 
actual value to the calculated value according to the code standard of vehicle load, $K_{\mathrm{SQ}}=\left(S_{\mathrm{Q}} / S_{\mathrm{OK}}\right)$. Here, $S_{\mathrm{Q}}$ represents the actual value and $S_{\mathrm{QK}}$ represents the calculated value according to the code standard of vehicle load effect. The dimensionless parameter $K_{\mathrm{SQ}}$ (shown in Table 1) of vehicle load under dense and general operating conditions can be obtained from [14].

When $T=100$ years, the time-varying mean and standard deviation model of vehicle load effect are as follows:

$$
\begin{aligned}
\mu_{\mathrm{SQ}}(t) & =\mu_{\mathrm{SQ}}(T)+\frac{[\ln (t / T)]}{\alpha_{T}}, \\
\sigma_{\mathrm{SQ}}(t) & =\sigma_{\mathrm{SQ}}(T), \\
\alpha_{T} & =\frac{\pi}{\sqrt{6} \sigma_{\mathrm{SQ}}(T)} .
\end{aligned}
$$

\section{Time-Varying Reliability Method}

The structural time-varying function is $Z(t)=R(t)-S_{G}-S_{Q}(t)$, where $R(t)$ represents the timevarying resistance that follows lognormal distribution, $S_{\mathrm{G}}$ represents the bridge deadweight that follows normal distribution, and $S_{\mathrm{Q}}(t)$ represents the live load of vehicle that generally follows extreme I distribution. When the function $Z(t)$ is greater than 0 , the structure is generally considered safe and reliable. When the function $Z(t)$ is less than 0 , the structure is in the state of failure and the failure probability of structure is the value of $Z(t)$. When the function $Z(t)$ is equal to 0 , the structure is at the limit state of bearing capacity. The relationship between the failure probability $p_{f}$ of structures and the reliability index $\beta$ is expressed as

$$
\beta=-\Phi^{-1}\left(P_{f}\right),
$$

where $\Phi^{-1}$ is the inverse function of normal distribution.

In this paper, the Monte Carlo method is used to iteratively calculate the reliability index through FERUM (Finite Element Reliability Using Matlab) software. The details of FERUM can be found in [27].

\section{Life Estimation Based on Inverse Reliability Method}

In this section, an inverse reliability method was proposed to estimate the residual life of bridges reinforced by CFRP in the service stage.

For a target reliability index $\beta_{\text {target }}$, the problem of estimation life $\gamma$ can be described as follows:

$$
\text { Find the safety factor } \gamma \text {, which }\left\{\begin{array}{l}
\operatorname{minimize} \beta_{\text {target }}=\|\mu\| \\
\text { subject to } Z(X, \theta)=0,
\end{array}\right.
$$

where $\|\cdot\|$ is the norm of a vector and $Z$ is the transformation of the limit state function $Z$ from the original space ( $X$ space) to the standard normal space ( $\mu$ space). $\mu$ is the vector of standard normal variables related to the design
TABle 1: Dimensionless parameter KSQ statistics.

\begin{tabular}{lcccc}
\hline Condition & Distribution type & $\mu$ & $\sigma$ & $\delta$ \\
\hline General & Extreme I & 0.6861 & 0.1076 & 0.1569 \\
Congestion & Extreme I & 0.7995 & 0.0689 & 0.0862 \\
\hline
\end{tabular}

point, $X$ is the vector of basic random variables, and $\theta$ is the design parameter.

The inverse FORM algorithm can be solved by the following recurrence relationship:

$$
\begin{aligned}
\mu^{k+1} & =\mu^{k}+\lambda^{k} \mathrm{~d} \mu^{k}, \\
\theta^{k+1} & =\theta^{k}+\lambda^{k} \mathrm{~d} \theta^{k}, \\
\mathrm{~d} \mu^{k} & =-\beta_{\text {target }} \frac{\nabla_{\mu} Z\left(\mu^{k}, \theta^{k}\right)}{\left\|\nabla_{\mu} Z\left(\mu^{k}, \theta^{k}\right)\right\|}-\mu^{k},
\end{aligned}
$$

$$
\mathrm{d} t^{k}=\frac{\left[\nabla_{\mu} Z\left(\mu^{k}, \theta^{k}\right), \mu^{k}\right]-Z\left(\mu^{k}, \theta^{k}\right)+\beta_{\text {target }}\left\|\nabla_{\mu} Z\left(\mu^{k}, \theta^{k}\right)\right\|}{\nabla_{\theta} Z\left(\mu^{k}, \theta^{k}\right)},
$$

where $\mu^{k}$ is the vector of standard normal variables related to the design point at the $k$ th iteration; $\theta^{k}$ is the deterministic design parameter at the $k$ th iteration; $\nabla_{\mu}$ is the vector of gradient operators with respect to $\mu ; \nabla_{\theta}$ is the vector of gradient operators with respect to $\gamma ;[$,$] is the inner product$ of two vectors; and $\theta^{k}$ is the step size at $k$ th iteration, which is determined through a line search algorithm. The iterative algorithm proceeds iteratively until convergence is reached, i.e., when

$$
\frac{\left(\left\|\mu^{k+1}-\mu^{k}\right\|^{2}+\left|\theta^{k+1}-\theta^{k}\right|^{2}\right)^{1 / 2}}{\left(\left\|\mu^{k+1}\right\|^{2}+\left|\theta^{k+1}\right|^{2}\right)^{1 / 2}} \leq \varepsilon
$$

where $\varepsilon$ is the convergence tolerance, and $\varepsilon=10^{-3}$ to $10^{-3}$ usually yields satisfactory $\gamma$ estimates. In this paper, the inverse reliability method is used to iteratively estimate the residual life of RC beam bridges by CFRP through the program of FERUM.

The steps involved in the proposed method for estimating residual life of RC beam bridges reinforced by CFRP are as follows:

(1) Select the initial values for the random variables and an unknown deterministic design parameter (based on engineering or statistical knowledge and/or assumptions). Mean values are often a reasonable choice for the random variables.

(2) Initialize the iteration counter to $k=1$.

(3) Calculate $Z(\mu, t)$.

(4) Solve (22) and (23) to obtain $d \mu^{k}$ and $d \theta^{k} \mathrm{~d} \theta^{k} d \theta k d \theta^{k}$.

(5) Substitute $d \mu^{k}$ and $d \theta^{k}$ into (20) and (21) to determine $\mu^{k+1}$ and $\theta^{k+1}$. 
(6) Check the convergence criterion using (24); if unsatisfied, update the iteration counter $k=k+1$ and go to Step 3; otherwise, STOP (end of calculation).

\section{Examples}

The example bridge is located in China. It is a T-type reinforced concrete simple-supported beam bridge which has already had 50 years of service life [28]. The environment can be expressed as $\mathrm{RH}=70 \%$ and temperature $T=20^{\circ} \mathrm{C}$ [29]. The length of the bridge is $100 \mathrm{~m}$, and the deck is composed of the $7.0 \mathrm{~m}$ roadway and the $2 * 0.15 \mathrm{~m}$ guardrail. There are five spans of the bridge with the $16.8 \mathrm{~m}$ span length. The section size of the bridge is shown in Figure 2. The concrete strength grade is C25, and the thickness of protective layer is $30 \mathrm{~mm}$. The layout of the main tensioned bars is $4 \phi 32$ and $2 \phi 16$ in 3 rows. The design load of the bridge is Highway-II grade upgraded from the original Vehicle-15 grade due to the rapid development of road transport in recent years. Now the bottom of the beam is strengthened with $1.2 \mathrm{~mm}$ CFRP sheet, whose modulus of elasticity is $165000 \mathrm{MPa}$ and ultimate tensile strength is $2800 \mathrm{MPa}$.

Only the side beam was analyzed because it carries the most unfavourable load. Assuming that the performance of CFRP is unchanged and the bridge corrosion is delayed by 15 years after reinforcement. The mean value and standard deviation of time-varying resistance can be obtained based on the calculating steps (shown in Table 2). The results are consistent with [28].

The mean and standard deviation of side girder dead load are $566.1751 \mathrm{kN} \cdot \mathrm{m}$ and $24.381 \mathrm{kN} \cdot \mathrm{m}$, respectively. The transverse distribution coefficients of the main girders were calculated, and the most unfavourable load of Highway-II grade was applied. Combining that with (17) and assuming that the bridge is in general operation state during $85 \%$ of the time and is in intensive operation state during the rest of the time, we can calculate the time-varying mean value and standard deviation of the vehicle load on the side girders (shown in Table 3). The results are consistent with [28].

The time-varying reliability index (shown in Table 4 and Figure 3) of bridges can be calculated by Monte Carlo method based on structural function. The time-varying failure probability of bridges is shown in Table 5. The calculation results are consistent with [28].

Figure 3 shows that after 50 years of service, the reliability index of the bridge is only 3.5764 and the failure probability $P_{f}$ is $1.7418 \times 10^{-4}$, which cannot satisfy the requirement of the code [30], where the reliability index should be greater than 4.2 and the failure probability less than $1.3346 \times 10^{-5}$. After reinforcement, the reliability index is rapidly increased to 4.611 , and the failure probability is $2.0037 \times 10^{-6}$. In the next 50 years, it can satisfy the requirements of reliability index and failure probability in the code. This shows that the reinforcement scheme is feasible. The results are consistent with [28].

In this paper, parameter sensitivity analysis of dead load and vehicle load was carried out. The influence of variation coefficient on bridge reliability index was mainly discussed.
From Figures 4 and 5, we can see that the reliability index decreases with the increase of variation coefficient. However, the reduction of vehicle load reliability index is particularly obvious. It is confirmed that the main reason for degradation of bridge performance at present is the increase of traffic volume. The variation coefficient of bridge dead load has little effect on the reliability index.

In the above analysis, the results of reliability assessment were used in the forward first reliability method, in which the expectancy life estimation was calculated using the trial and error that was redundancy. Here, the expected life was estimated using the proposed method based on the inverse reliability approach. For example, a different target reliability index was recommended for the target reliability, and the residual life of the bridge can be seen in Table 6. From Table 6 , it can be concluded that the residual life of the example bridge was close to the results of Table 4 because the target reliability was almost the same and the results are validated by forward reliability analysis. The calculation results are consistent with [28].

The results of residual life estimation of $\mathrm{RC}$ beam bridge reinforced by CFRP at the service stage from Table 6 indicate that, with increasing of the target reliability index, the remaining life estimation of $\mathrm{RC}$ beam bridge reinforced by CFRP at the service stage is expected to decrease. For more precise remaining life estimation of RC beam bridge reinforced by CFRP at the service stage, it is necessary to develop the analysis technique considering the effect of structural parameter randomness. This is very important for reasonable residual life estimation of RC beam bridges reinforced by CFRP at the service stage, which exhibit wide dispersion in structural parameters. This problem can be solved by the proposed method. The proposed method is more robust and reliable than the traditional method.

A parametric analysis was carried out to study the influence of the mean value of random variables and the coefficients of variation of random variables on the residual life estimation of RC beam bridge reinforced by CFRP at the service stage. For the sake of simplicity, only strengthening bridge at the target reliability 4.2 in the previous section is considered.

When keeping the coefficients of variation of all random variables unchanged and only varying the mean values under a $\pm 15 \%$ of all random variables, the residual life estimations of RC beam bridge reinforced by CFRP at the service stage are compared in Figures 6-8. With the increase of the mean value of random variables of dead load and live load, the residual life estimation of $\mathrm{RC}$ beam bridge reinforced by CFRP at the service stage is expected to decrease. While an opposite influence can be observed for the random variables of CFRP. With the increase of the mean value of the random variables of CFRP, the residual life estimation of RC beam bridge reinforced by CFRP at the service stage is expected to increase.

By varying the coefficients of variation of random variables, the residual life of $\mathrm{RC}$ beam bridge reinforced by CFRP at the service stage is estimated using the proposed method mentioned previously. When keeping the mean values of all random variables unchanged and only varying 


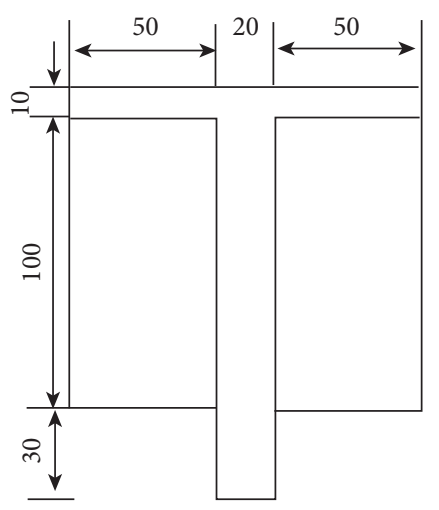

(a)

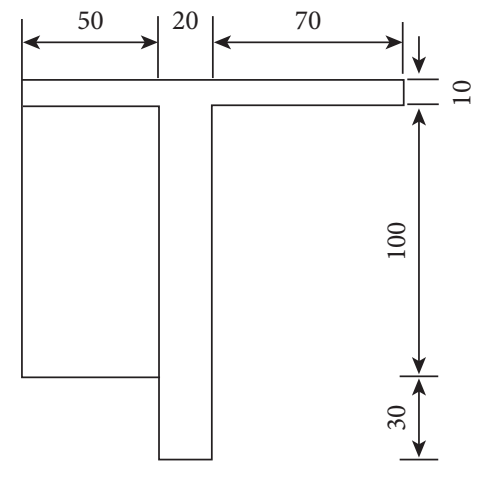

(b)

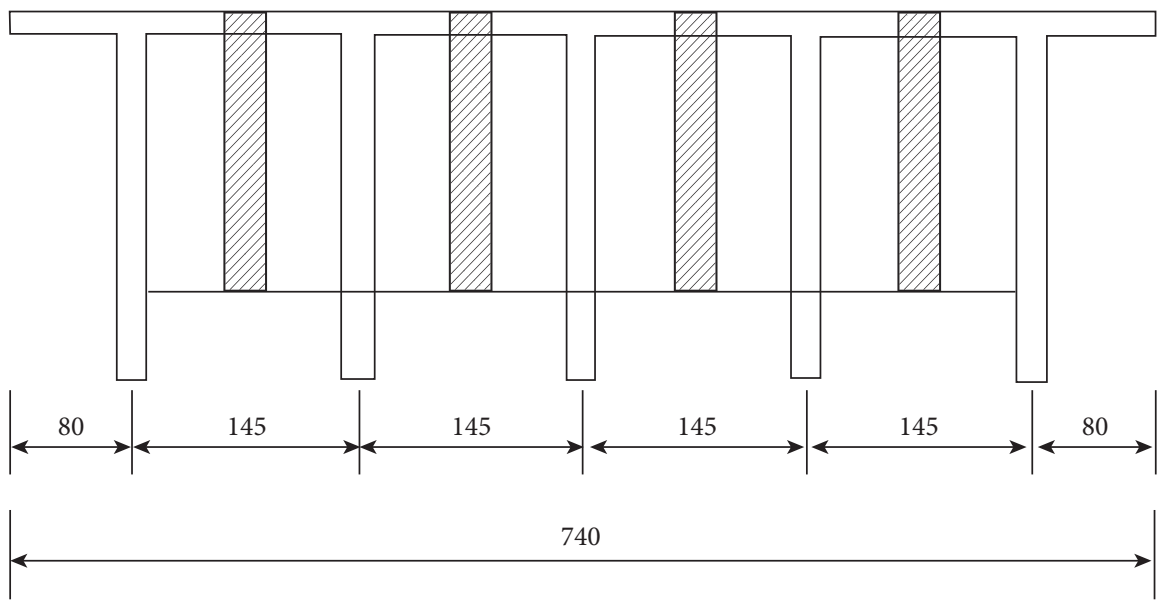

(c)

Figure 2: Cross section drawings (unit: $\mathrm{cm}$ ). (a) Middle girder. (b) Side girder. (c) Girder cross section.

TABLE 2: Mean and standard deviation of resistance $(\mathrm{kN} \cdot \mathrm{m})$.

\begin{tabular}{|c|c|c|c|c|c|}
\hline \multirow{2}{*}{ Time/year } & \multicolumn{2}{|c|}{ Unstrengthening } & \multirow{2}{*}{ Time/year } & \multicolumn{2}{|c|}{ Strengthening } \\
\hline & $\mu_{\mathrm{SQ}}$ & $\sigma_{\mathrm{SQ}}$ & & $\mu_{\mathrm{SQ}}$ & $\sigma_{\mathrm{SQ}}$ \\
\hline 10 & 1917.4 & 208.77 & 50 & 2113.5 & 204.24 \\
\hline 20 & 1910.9 & 208.06 & 60 & 2113.5 & 204.24 \\
\hline 30 & 1882.3 & 204.95 & 70 & 2101.2 & 202.90 \\
\hline 40 & 1853.9 & 201.89 & 80 & 2065.0 & 198.97 \\
\hline 50 & 1825.7 & 198.85 & 90 & 2040.6 & 196.33 \\
\hline & & & 100 & 2016.2 & 193.68 \\
\hline
\end{tabular}

TABLE 3: Mean and standard deviation of the vehicle load $(\mathrm{kN} \cdot \mathrm{m})$.

\begin{tabular}{lcc}
\hline Time/year & $\mu_{\mathrm{SQ}}$ & $\sigma_{\mathrm{SQ}}$ \\
\hline 10 & 441.6469 & 75.5772 \\
20 & 482.4949 & 75.5772 \\
30 & 506.3878 & 75.5772 \\
40 & 523.3402 & 75.5772 \\
50 & 536.4894 & 75.5772 \\
60 & 547.1332 & 75.5772 \\
70 & 556.3168 & 75.5772 \\
80 & 564.1855 & 75.5772 \\
90 & 571.1261 & 75.5772 \\
100 & 577.3347 & 75.5772 \\
\hline
\end{tabular}

TABLE 4: The beam time-dependent reliability index.

\begin{tabular}{lccc}
\hline Time/year & Unstrengthening $\beta$ & Time/year & Strengthening $\beta$ \\
\hline 10 & 4.23 & 50 & 4.61 \\
20 & 4.06 & 60 & 4.57 \\
30 & 3.88 & 70 & 4.51 \\
40 & 3.72 & 80 & 4.38 \\
50 & 3.58 & 90 & 4.29 \\
& & 100 & 4.20 \\
\hline
\end{tabular}






FIgure 3: The time-dependent reliability index.

TABLe 5: The beam time-dependent failure probability.

\begin{tabular}{lccc}
\hline Time/year & $\begin{array}{c}\text { Unstrengthening } \\
\beta /\left(\times 10^{-5}\right)\end{array}$ & Time/year & $\begin{array}{c}\text { Strengthening } \\
\beta /\left(\times 10^{-5}\right)\end{array}$ \\
\hline 10 & 1.15 & 50 & 0.20 \\
20 & 2.46 & 60 & 0.24 \\
30 & 5.22 & 70 & 0.33 \\
40 & 9.86 & 80 & 0.59 \\
50 & 17.42 & 90 & 0.90 \\
& & 100 & 1.35 \\
\hline
\end{tabular}

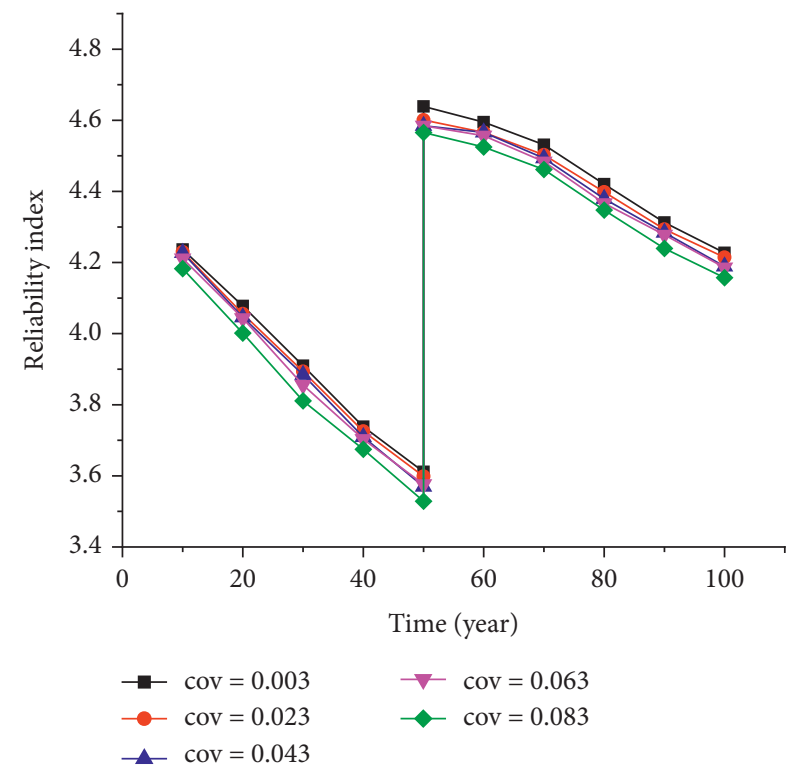

FIGURE 4: Influence of variation coefficients of reliability index of the dead load.

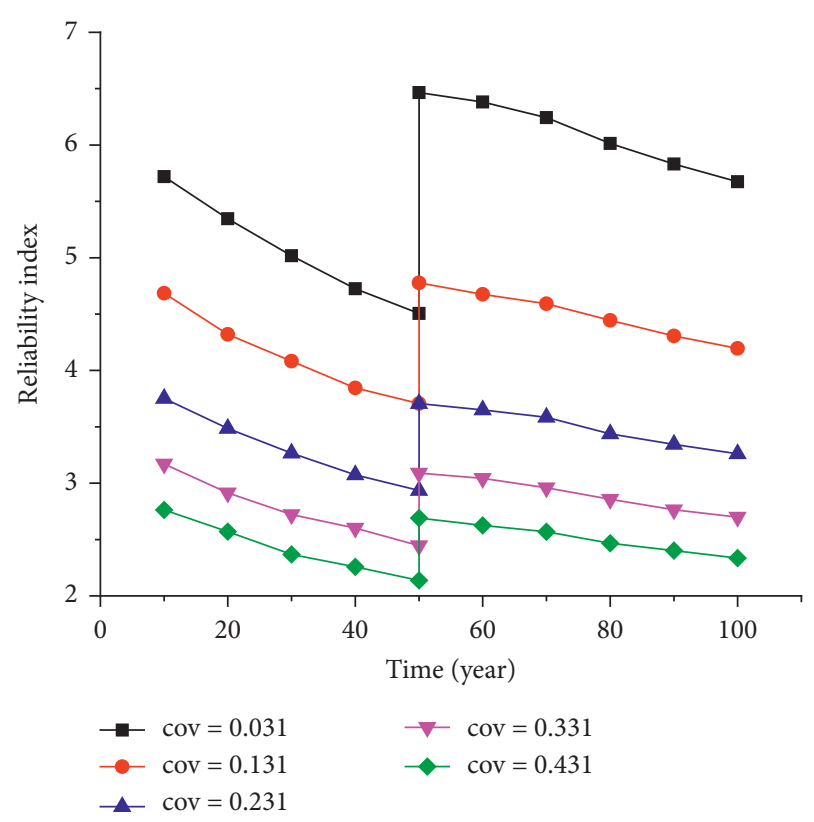

Figure 5: Influence of vehicle load variation coefficients of reliability index.

TABLE 6: Life estimation based on the target reliability index.

\begin{tabular}{lccc}
\hline $\begin{array}{l}\text { Target } \beta \\
\text { (unstrengthening) }\end{array}$ & $\begin{array}{c}\text { Residual } \\
\text { life }\end{array}$ & $\begin{array}{c}\text { Target } \beta \\
\text { (strengthening) }\end{array}$ & $\begin{array}{c}\text { Residual } \\
\text { life }\end{array}$ \\
\hline 4.2 & 10.2 & 4.60 & 50.2 \\
4.1 & 19.5 & 4.55 & 60.3 \\
3.9 & 29.6 & 4.50 & 70.1 \\
3.7 & 40.5 & 4.40 & 79.6 \\
3.6 & 49.7 & 4.30 & 89.8 \\
& & 4.20 & 100 \\
\hline
\end{tabular}

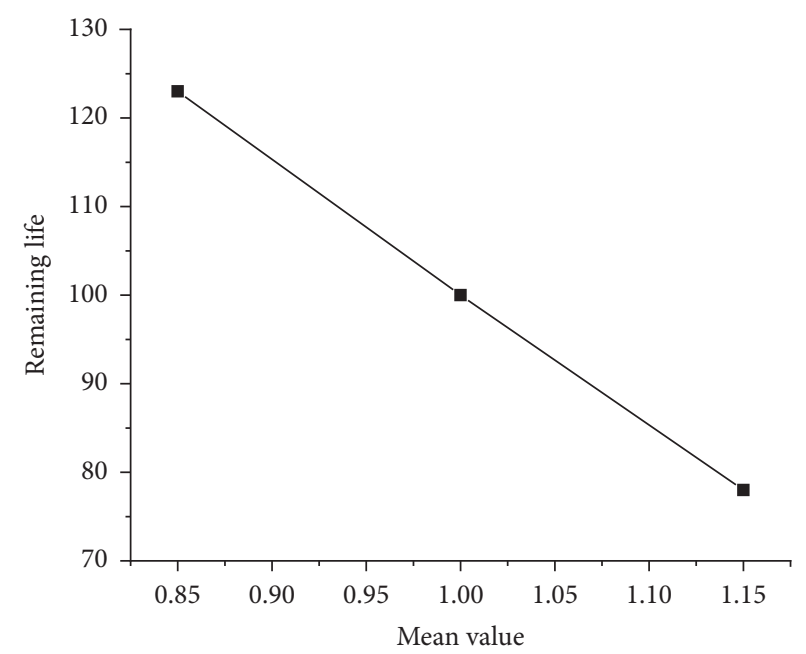

FIGURE 6: Influence of mean value of dead load. 


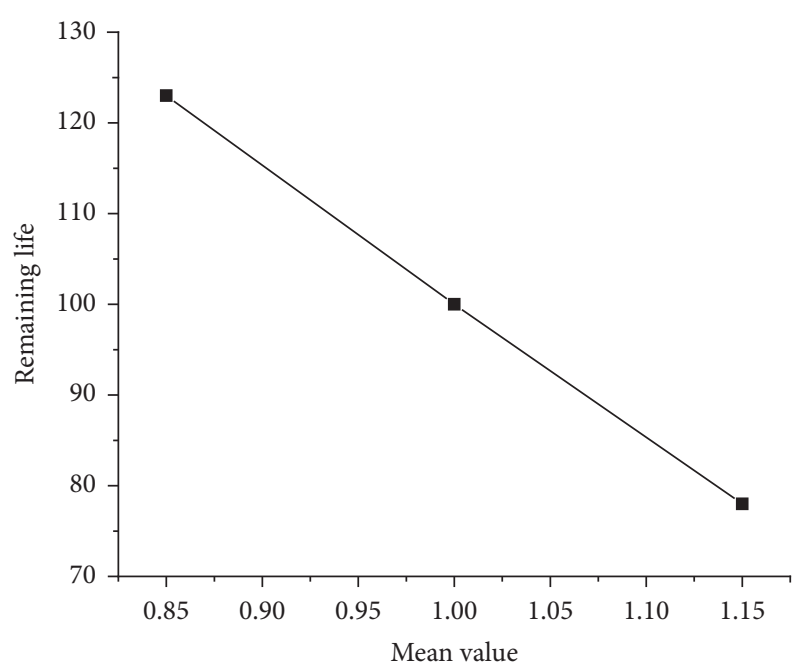

Figure 7: Influence of mean value of live load.

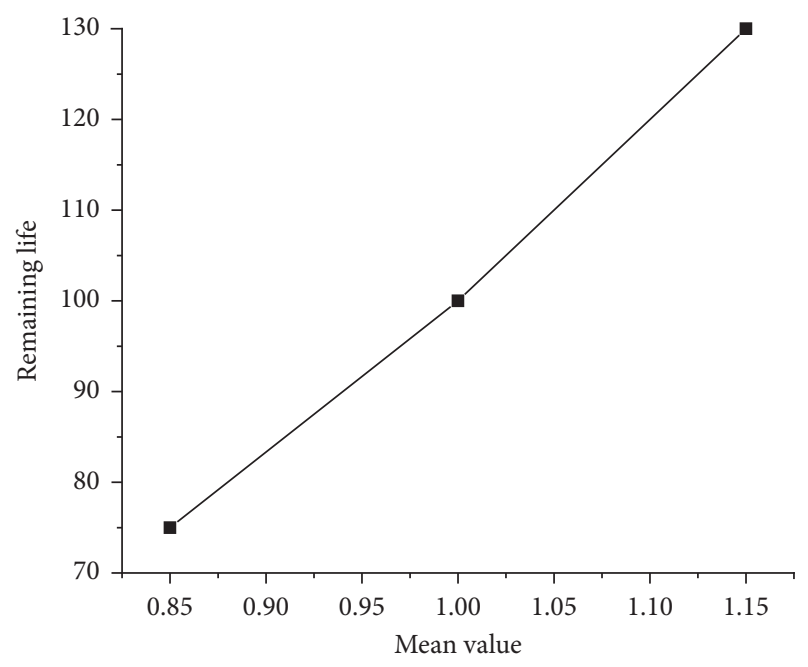

FIGURE 8: Influence of mean value of CFRP.

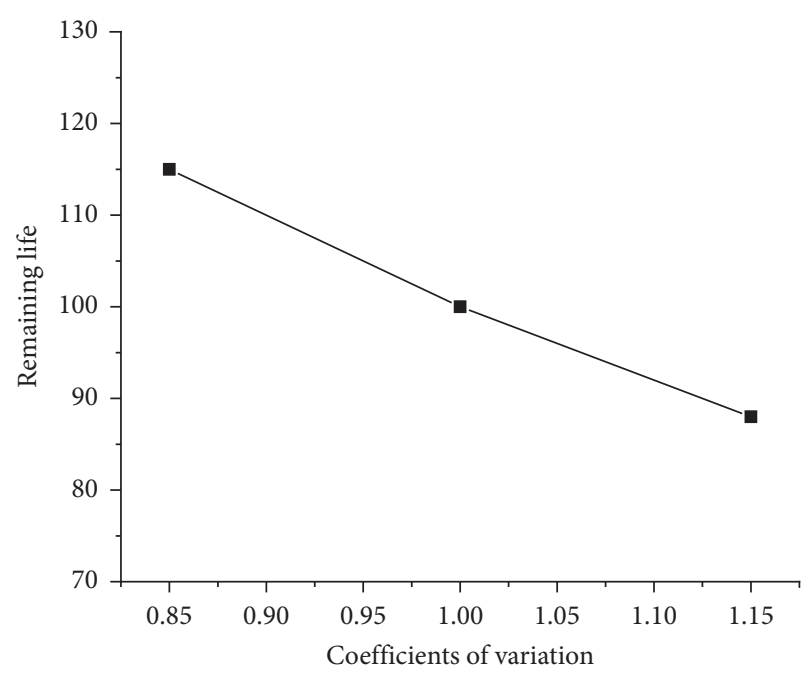

FIGURE 9: Influence of coefficients of variation of dead load.

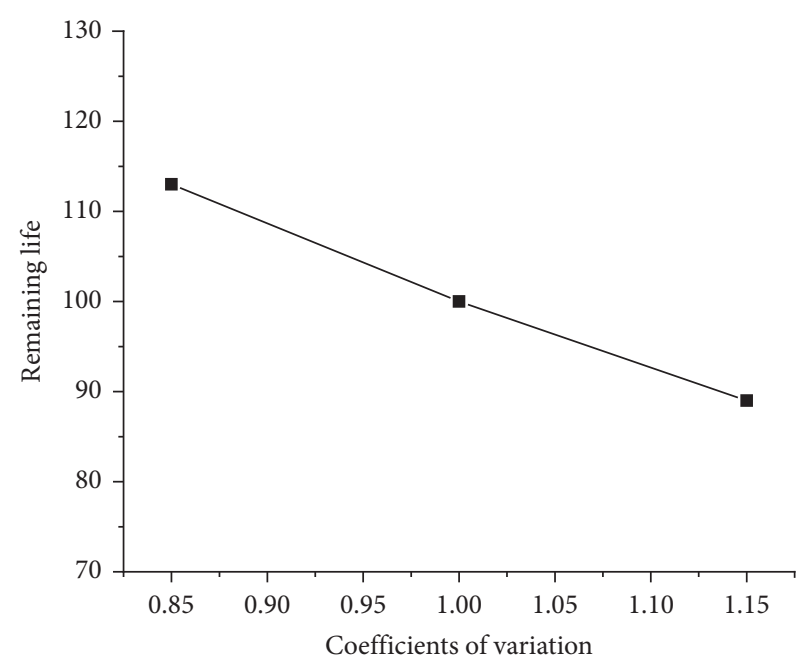

FIGURE 10: Influence of coefficients of variation of live load.

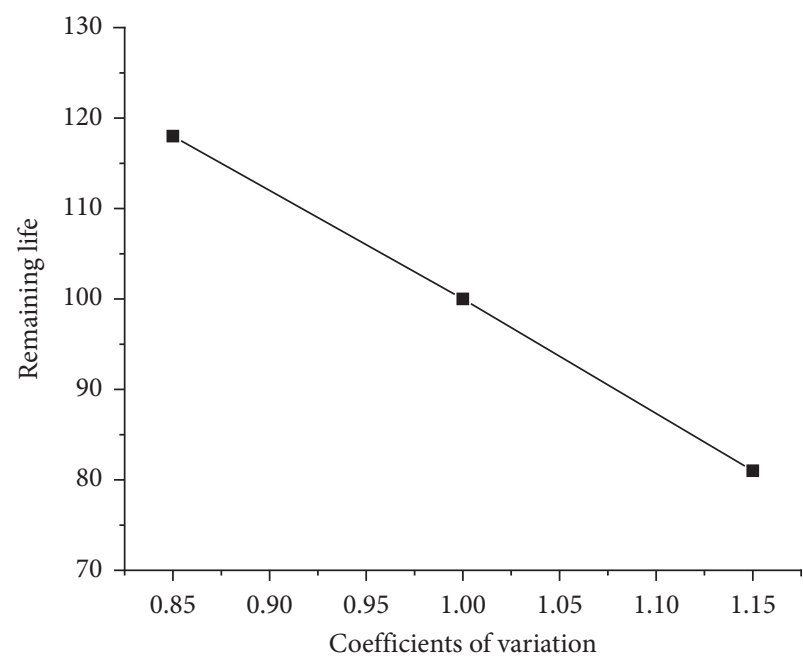

FIGURE 11: Influence of coefficients of variation of CFRP.

the coefficients of variation under a $\pm 15 \%$ of all random variables. The results are illustrated in Figures 9-11. It is observed that the residual life estimation of RC beam bridge reinforced by CFRP at the service stage decreases as the coefficients of variations of all random variables increase.

\section{Conclusion}

In this study, a new method is proposed to estimate the reliability of RC bridge strengthened by CFRP, and uncertainties of material properties, geometry parameters, load model, and time-dependent resistance model are taken into account. The proposed method combines the concepts of inverse reliability and the calculation method of load and resistance of RC bridge strengthened by CFRP. A RC bridge strengthened by CFRP is selected as an example to verify the proposed method, and the main conclusions and findings can be summarized as follows. 
(1) Based on the limit state function established in this paper, the Monte Carlo method is used to calculate the reliability index of the RC bridge strengthened by CFRP.

(2) Taking an existing T-beam bridge as an example, the time-varying reliability before and after reinforcement is calculated. Results show that the reliability index decreases with aging. After strengthening the RC bridge using CFRP, the reliability index will increase.

(3) The effects of various parameters on the reliability of $\mathrm{RC}$ bridge strengthened by CFRP during the service stage are analyzed. The results indicate that the variation coefficient of dead load, vehicle load, and cross-sectional area of corroded steel bars could affect the reliability of the RC bridge. Additionally, it is found that the variation coefficient of live load is more important than that of dead load and crosssectional area of corroded steel bars.

(4) For more precise residual life estimation of RC girder bridge reinforced by CFRP at the service stage, it is necessary to develop analysis technique considering the effect of structural parameter randomness. The proposed method is more robust and reliable than the traditional method.

\section{Data Availability}

The data supporting the conclusions of the study are included within the manuscript.

\section{Conflicts of Interest}

The authors declare that there are no conflicts of interest regarding the publication of this paper.

\section{Acknowledgments}

The authors would like to acknowledge the financial support from the Fundamental Research Funds for the Central Universities (Grant no. 300102210105), Natural Science Basic Resarch Program of Shaanxi (Program no. 2020JQ377), Guangdong Provincial Transportation and Transportation Office Technology Funding Project (2016-02-016), and Shanxi Natural Science Basic Research Funding Project (201801D221217).

\section{References}

[1] M. Duan, S. Zhang, X. Wang, and F. Dong, "Mechanical behavior in perfobond rib shear connector with UHPC-steel composite structure with coarse aggregate," KSCE Journal of Civil Engineering, vol. 24, no. 4, pp. 1255-1267, 2020.

[2] K. Gajdosova and J. Bilcik, "Full-scale testing of CFRPstrengthened slender reinforced concrete columns," Journal of Composites for Construction, vol. 17, no. 2, pp. 239-248, 2013.

[3] J.-G. Dai, Y.-L. Bai, and J. G. Teng, "Behavior and modeling of concrete confined with FRP composites of large deformability," Journal of Composites for Construction, vol. 15, no. 6, pp. 963-973, 2011.
[4] K. Karimi, M. J. Tait, and W. W. El-Dakhakhni, "Testing and modeling of a novel FRP-encased steel-concrete composite column," Composite Structures, vol. 93, no. 5, pp. 1463-1473, 2011.

[5] Z.-Y. Sun, G. Wu, Z.-S. Wu, and M. Zhang, "Seismic behavior of concrete columns reinforced by steel-FRP composite bars," Journal of Composites for Construction, vol. 15, no. 5, pp. 696-706, 2011.

[6] P. Delgado, A. Arêde, N. Vila Pouca, P. Rocha, A. Costa, and R. Delgado, "Retrofit of RC hollow piers with CFRP sheets," Composite Structures, vol. 94, no. 4, pp. 1280-1287, 2012.

[7] D.-S. Gu, G. Wu, Z.-S. Wu, and Y.-F. Wu, "Confinement effectiveness of FRP in retrofitting circular concrete columns under simulated seismic load," Journal of Composites for Construction, vol. 14, no. 5, pp. 531-540, 2010.

[8] P. Kumar, K. Mosalam, S. Abbasi et al., Structures Congress 2014-Reinforced Concrete Bridge Columns Repaired with Fiber-Reinforced Polymer Jackets, pp. 429-440, American Society of Civil Engineers Structures Congress, Boston, MA, USA, 2014.

[9] P. Baah, "Development of innovative CFRP prestressed decked bulb T beam bridge system," M.S. thesis, Lawrence Technological University, Southfield, MI, USA, 2012.

[10] N. Grace, T. Enomoto, P. Baah, and M. Bebawy, "Flexural behavior of CFRP precast prestressed decked bulb T-beams," Journal of Composites for Construction, vol. 16, no. 3, pp. 225-234, 2012.

[11] N. Grace, M. Bebawy, and K. Ushijima, "Field application of composite post-tensioning system," Concrete International, vol. 36, 2014.

[12] X. Yang, P. Zohrevand, A. Mirmiran et al., "Comparative study of unbonded carbon fiber and steel strands in posttensioned pier caps," Journal of Composites for Construction, vol. 20, no. 1, 2015.

[13] X. Yang, P. Zohrevand, A. Mirmiran et al., "Posttensioning of segmental bridges using carbon-fiber-composite cables," $P C I$ Journal, vol. 60, no. 3, pp. 50-62, 2015.

[14] X. Y. Sun, C. K. Huan, and B. S. Sun, "Time-dependent reliability and analysis of existing bridges strengthened with FRP laminates," Journal of Southeast University: Natural Science Edition, vol. 31, no. 1, pp. 427-432, 2005.

[15] B. Du, R. D. Zhao, and Z. H. Huang, "Reliability research of carbon fiber reinforced polymer in bridge strengthening," in Proceedings of the National Civil Engineering Graduation of the Fifth National Academic Forum, Hunan University Press, Changsha, China, pp. 271-273, 2007.

[16] F. Forouzannia, B. Gencturk, M. Dawood et al., "Calibration of flexural resistance factors for load and resistance factor design of concrete bridge girders prestressed with carbon fiber-reinforced polymers," Journal of Composites for Construction, vol. 20, no. 2, 2016.

[17] D. T. Niu and Y. Q. Cheng, "Model and reliability analysis for carbonation of concrete structures," Journal of Xian University of Science and Technology, vol. 27, no. 4, pp. 365-369, 1995.

[18] J. X. Peng, X. D. Shao, and J. R. Zhang, "Time-dependent reliability of pretensioned prestressed concrete bridge girders subject to carbonation-induced corrosion considering climate change," Journal of Changsha University and Technology: Natural Science, vol. 7, no. 2, pp. 33-42, 2010.

[19] P. Thoft-Christensen, F. M. Jensen, and C. R. Middleton, "Assessment of the reliability of concrete slab bridges," Reliability and Optimization of Structural Systems, pp. 321-328, Pergamon Press, New York, NY, USA, 1997. 
[20] L. Wang, Research on Time-Variant Reliability of Existing $R C$ Beam Bridge under Fuzziness and Randomness, Changsha University of Science and Technology, Changsha, China, 2008.

[21] M. G. Stewart, "Mechanical behaviour of pitting corrosion of flexural and shear reinforcement and its effect on structural reliability of corroding RC beams," Structural Safety, vol. 31, no. 1, pp. 19-30, 2009.

[22] H. Chi Li, Y. Sun, and Y. Z. Wang, "Reinforcing bar corrosion models of RC structures and effect factors," Port Engineering Technology, no. 1, pp. 17-21, 2007.

[23] D. T. Niu, Durability and Life Forecast of Reinforced Concrete Structure, pp. 65-66, Beijing Science Press, Beijing. China, 2003.

[24] D. T. Liu and Q. L. Wang, "Models of concrete strength changing with time in general air environment," Industrial Construction, vol. 25, no. 6, pp. 36-38, 1995.

[25] Ya F. Ma, Probability Model of Resistance Attenuation for Existing RC Bridge Member Based on Information Updating, Changsha University of Science and Technology, Changsha, China, 2011.

[26] GB/T 50283-1999, Unified Standard for Reliability Design of Highway Engineering Structures.

[27] Z. L. Luo and F. H. Dong, "Statistical investigation of bearing capacity of pile foundation based on bayesian reliability theory," Advances in Civil Engineering, vol. 2019, Article ID 9858617, 7 pages, 2019.

[28] J. R. Zhang, J. Mao, J. X. Peng, and H. Peng, "Reliability index analysis of the service process of RC beam bridge reinforced by carbon fiber," Journal of Changsha University of Science and Technology (Natural Science), vol. 11, no. 2, pp. 25-31, 2013.

[29] Ministry of Communications of the People's Republic of China, Code for Design of Highway Reinforced Concrete and Prestressed Concrete Bridges and Culverts (JTG 3362-2018), Ministry of Communications of the People's Republic of China, Beijing, China, 2018.

[30] Ministry of Communications of the People's Republic of China, Unified Standard for Reliability Design of Highway Engineering Structures, Ministry of Communications of the People's Republic of China, Beijing, China, 2020. 